\title{
Congenital bilateral ectopic parotid glands: case report and systematic review of the literatures
}

\author{
Shang Xie", Zi-Meng Li", Shi-Jun Li, Zhi-Gang Cai \\ Department of Oral and Maxillofacial Surgery, Peking University School and Hospital of Stomatology \& National Clinical Research Center for Oral \\ Diseases \& National Engineering Laboratory for Digital and Material Technology of Stomatology \& Beijing Key Laboratory of Digital Stomatology, \\ Beijing, China \\ \#These authors contributed equally to this work. \\ Correspondence to: Zhi-Gang Cai. Department of Oral and Maxillofacial Surgery, Peking University School and Hospital of Stomatology, 22\# \\ Zhongguancun South Avenue, Haidian District, Beijing 100081, China. Email: c2013xs@163.com.
}

\begin{abstract}
Cheek swelling can be attributed to several pathologies, including masseteric hypertrophy, diffuse inflammatory changes and neoplasia. We report an extremely rare case of bilateral cheek swelling as a result of ectopic parotid glands. This case is a young female patient with bilateral ectopic parotid glands superficial to the masseter muscle and the zygomatic arch, demonstrated by the enhanced computed tomography (CT). Medical history, clinical features, videography and management of this case are described. After two years of observation, no significant change in symptoms was observed on this patient. Besides, we conducted a case report and systematic review of cases of ectopic parotid gland. A literature search was performed using PubMed, Web of Science, and Ovid electronic database. A total of 144 papers were retrieved and only one paper was included in the systematic review. In conclusion, bilateral ectopic parotid gland is extremely rare and easily confused with other lumps in the area of head and neck. CT, magnetic resonance imaging (MRI), ultrasound imaging and parotid sialography allow for noninvasive diagnosis of ectopic parotid gland. If the parotid ectopic is highly suspected and the patient does not have obvious symptoms, conservative treatment and long-term observation follow-up are recommended.
\end{abstract}

Keywords: Ectopic parotid gland; case report; systematic review

Submitted Oct 09, 2020. Accepted for publication Jan 24, 2021.

doi: $10.21037 /$ gs-20-751

View this article at: http://dx.doi.org/10.21037/gs-20-751

\section{Introduction}

The parotid gland is the largest salivary gland lying posterior to the mandibular ramus and anterior to the mastoid process of temporal bone. The facial nerve and its branches travel in the parotid gland, dividing it into superficial and deep lobes. Functionally, it secretes serous saliva through the parotid duct into oral cavity, facilitating mastication and swallowing. Absence or dysfunction of the parotid glands may be asymptomatic but usually would result in failure of salivary secretion, commonly leading to symptoms of xerostomia, dysphagia, oral candidiasis, halitosis and periodontal disease $(1,2)$.

Anatomic variations of parotid gland are a rare condition, though some previous cases reported ectopia that accessory parotid tissue was associated with aplasia of the main parotid gland (3-5). The accessory gland is characterized by parotid tissue with a diameter of $3 \mathrm{~cm}$ or less, which is not continuous with the main body of the parotid gland but still draining into Stenson's duct. It typically lies several millimeters anterior to the main parotid gland and superficial to the masseter muscle, along the course of the buccal branch of facial nerve (6-9). Aplasia of the parotid gland may be partial or total, unilateral or bilateral, with accessory salivary tissue or with several developmental syndromes (10-13). This article aimed to report a rare case of bilateral ectopic parotid gland. 
We present the following case in accordance with the CARE reporting checklist (available at http://dx.doi. org/10.21037/gs-20-751).

\section{Case presentation}

In January 2018, a 12-year-old female was referred to the Department of Oral and Maxillofacial Surgery at Peking University School and Hospital of Stomatology for bilateral spontaneously-developed buccal swelling in the upper masseteric regions of 8 year's duration. Her family and medical history was non-contributory and the patient reported no symptoms of pain, xerostomia, purulence, redness and local heat. Little attention was paid by the patient and her family until facial asymmetry was observed.

Physical examination revealed spherical swellings which were soft and mobile in bilateral upper masseteric regions, approximately $6 \times 6 \mathrm{~cm}$ in dimension (Figure $1 A$ ). Tenderness, sign of neoplasm and cervical lymphadenopathy were negative on palpation. The texture of the skin surface was normal, and there was no facial palsy or cheek fistula. Intraoral examination showed both parotid papillae in situ without signs of inflammation, and an adequate amount of clear saliva was observed.

Enhanced CT scan revealed that the left parotid gland was absent from the parotid space; only adipose tissue and normal lymphoid tissue were seen (Figure $1 B$, white arrow). Density of the image of the left bulge superficial to ipsilateral masseter muscle and zygomatic bone was same to that of parotid gland (Figure 1B, red arrow). In addition, the glandular tissue in the right parotid space was also significantly dysplastic comparing to normal gland, and the main part of parotid gland tissue connected to it was in the same position as the contralateral side (Figure 1B). Mandible angles, ramus and condylar process all display asymmetry, with the left side being poorly developed.

Taking all radiographic appearance and clinical examinations into consideration, we highly suspected that patients had bilateral ectopic parotid glands. In view of the young age and the normal salivary function of this patient, no surgical treatment was indicated. The patient had been followed up 2 years later and the swelling on the bilateral face showed no significant changes (Figure 1C,D). The patient agrees to the current treatment decision and regular follow-up. All procedures performed in this study involving human participants were in accordance with the ethical standards of the institutional committee, and with the Helsinki Declaration (as revised in 2013). Written informed consent was obtained from the patient's guardian (Child's father) for publication for this case report and any accompanying images.

\section{Discussion and conclusions}

To comprehensively understand the clinical features of bilateral ectopic parotid gland, we did a systematic review of ectopic parotid gland to discuss its clinical characteristics and treatment.

\section{Literature search}

A literature search was performed by 2 authors independently (SX and ZML) using PubMed, Web of Science, and Ovid electronic database with the terms: ectopic parotid gland. There was no year and language restriction and the last literature search of those databases was updated in Feb 3rd, 2020.

Firstly, all titles and abstracts of the retrieved articles were reviewed by 2 authors (SX and ZML). Full texts of the articles considered eligible for inclusion were accessed for further evaluation. Secondly, all the references of the related articles were reviewed to identify relevant studies that were not found by initial search. Then, relevant data were obtained from all selected articles by 2 authors (SX and ZML): age at diagnosis, gender, clinical features, clinical diagnosis, treatment, duration of follow-up, and outcome.

\section{Results}

The flowchart for selection of articles for systematic review is presented in Figure 2. A total of 144 papers were retrieved, of which, 118 studies were excluded based on duplicates, titles, and abstracts. After scanning the full texts, 16 papers related to unilateral ectopic parotid gland and 11 papers about accessory parotid gland were excluded. Finally, only one case of bilateral ectopic parotid gland from one article was included in this systematic review (14). The article was a case report of congenital parotid ectopia in accessory maxilla and facial cleft anomalies.

\section{Systematic review of reported cases}

The main clinical characteristics of bilateral ectopic parotid gland case from the selected articles for the systematic review were reported as follow. The only case was a 5 -month-old boy with lateral facial cleft on the right side, 

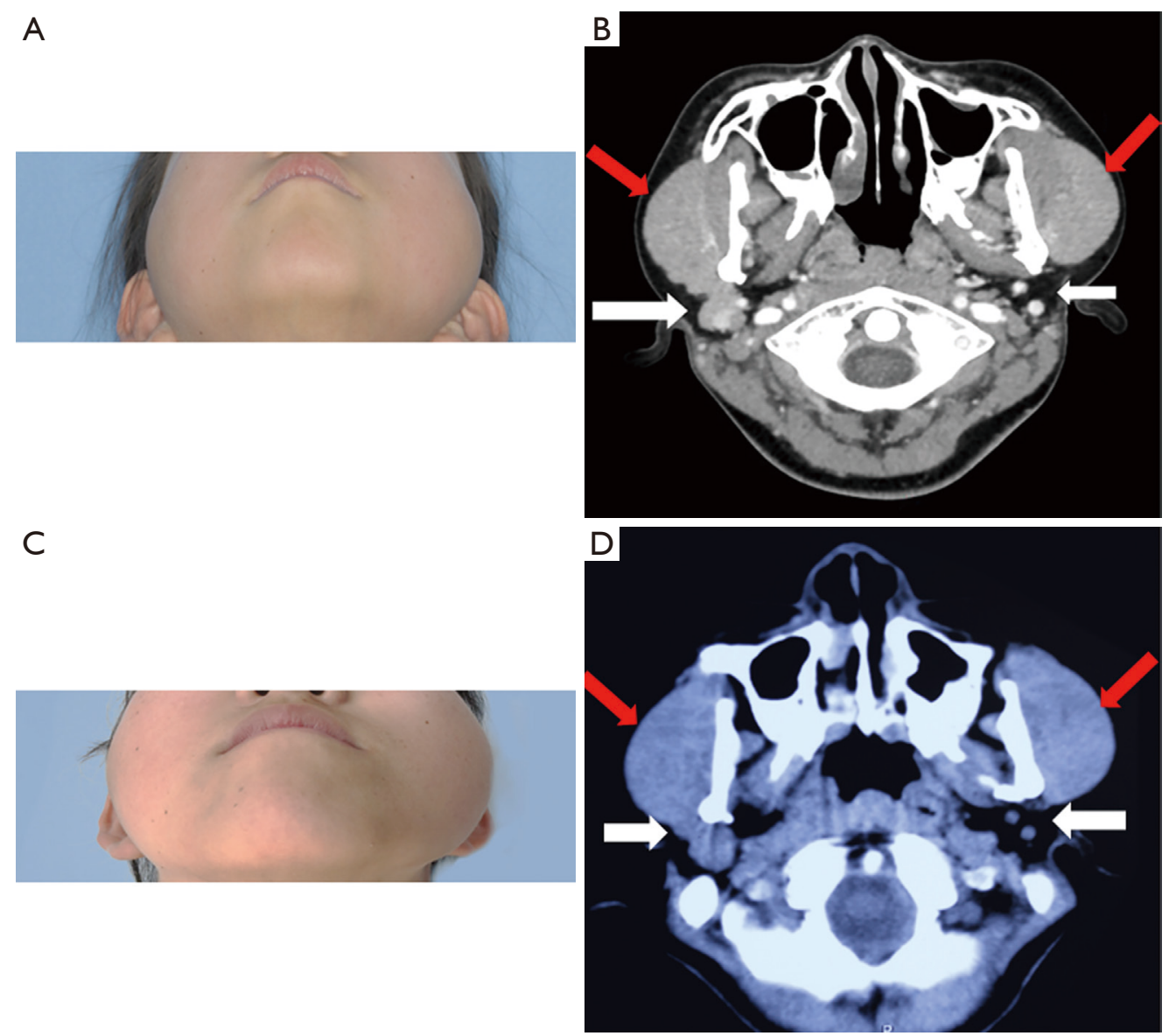

Figure 1 Clinical images and CT examinations. (A) Photographs show spherical swellings in bilateral upper masseteric regions; (B) the left parotid gland was absent from the parotid space, with adipose tissue and normal lymphoid tissue in the space (white arrow, left). The parotid tissue in the right parotid space was significantly dysplastic compared to the normal gland, and the main part of parotid gland tissue connected to it was in the same position as the contralateral side (white arrow, right). The main part of bilateral parotid glands appeared superficial to the masseter muscle and zygomatic bones (red arrows); (C,D) after one year of follow-up, the swelling of the bilateral side was not significantly increased. Meanwhile, the patient did not experience symptoms of discomfort during this year.

who then underwent cheiloplasty at 5 months old. The patient was recalled for examination at the age of 2 and was found that bilateral zygomatic arch slightly enlarged. CT images showed that bilateral parotid glands in the main parotid spaces were replaced by fat tissue. Soft tissue masses with gland attenuation indicating ectopic parotid glands were found below bilateral zygoma. No further treatment was reported for this case.

The primordial parotid glands are the first salivary glands to develop, commencing in embryonic development, at 4-6 weeks of prenatal period. They originate from the ectoderm of the oral cavity and evolve from oral epithelium proliferations which develop as cord-like strands into the underlying ectomesenchyme. Disruptions or affection in embryonic development of the parotid glands, most commonly appear to be unilateral, may result in variations in the location and morphology of parotid gland (1,5,15-19).

Variation of parotid gland in anatomy is a rare condition. In reported literatures, "ectopic" parotid glands often represent "aberrant" or "heterotopic" parotid gland tissue. Aberrant or heterotopic parotid gland tissue has been reported at various locations throughout the body, including the mandible and masseter muscle, hypophysis, lymph nodes, external and middle ear, Stafne bone cavity, thyroid gland, parathyroid gland, thyroglossal duct, lower neck, supra-clavicular and even some regions far from the head 


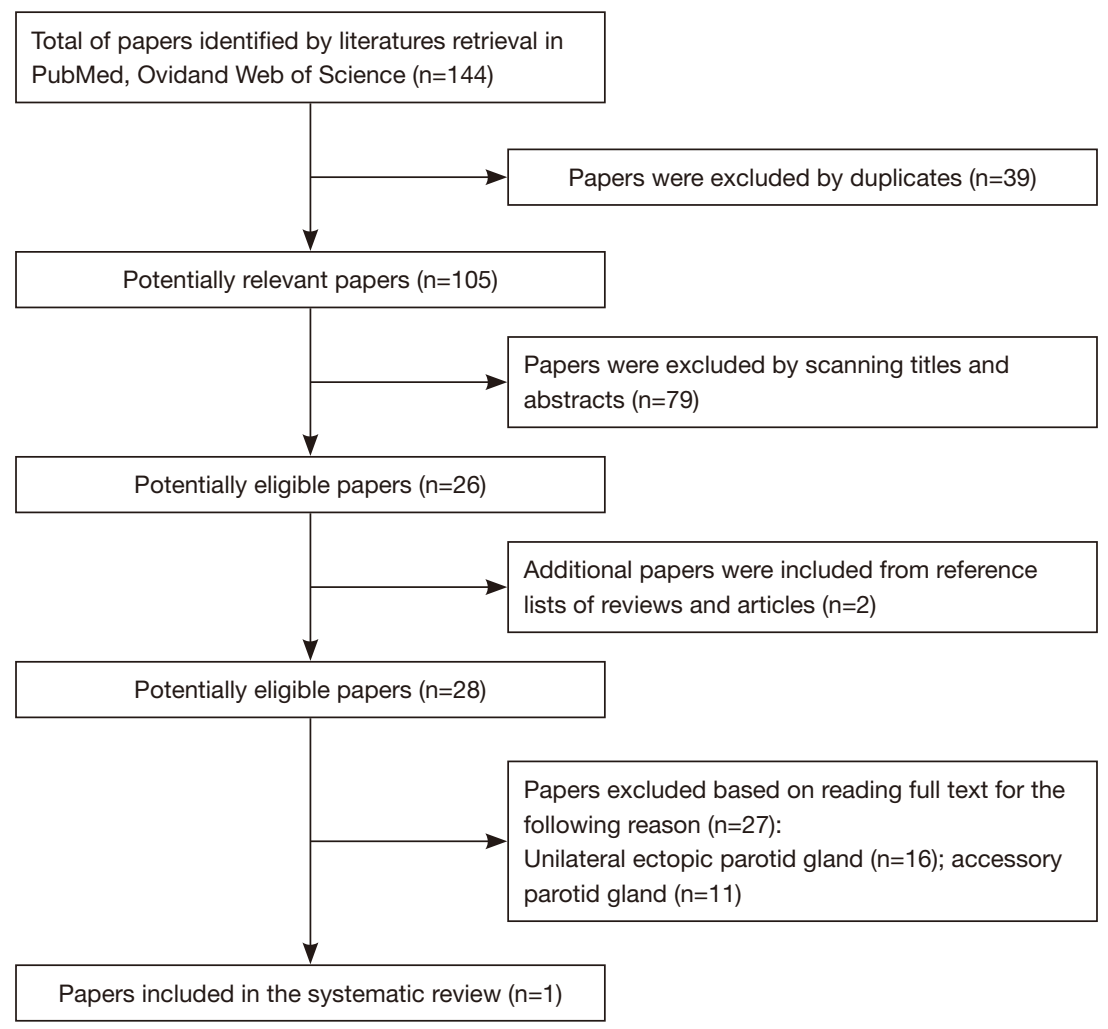

Figure 2 Flowchart of articles for our literature search from initial identification through final selection for review.

and neck (14,20-25). However, ectopia of whole parotid gland is extremely uncommon, especially for bilateral ectopic parotid glands.

Some previously reported associations of accessory parotid tissue with aplasia of the main parotid gland showed features of whole parotid gland ectopia $(1,3-5,18)$. However, whether the position variation in this case is aplasia of parotid glands with accessory glands hyperplasia or ectopic growth of parotid glands is still unclear (16). Accessory parotid gland has been described as parotid tissues with a diameter of $3 \mathrm{~cm}$ or less which are disconnected to main body of the parotid gland and drains to Stenson's duct. It typically lies several millimeters anterior to the main parotid gland and superficial to the masseter muscle, along the course of buccal branch of the facial nerve. Approximately $20 \%$ of the normal population has this structure. Histologically and radiologically, accessory parotid tissue is similar to normal parotid gland, and $1-7 \%$ of parotid tumors originate from accessory parotid pathologically $(6-9,26)$. Accessory salivary gland often occurs in patients with salivary gland aplasia. Parotid gland aplasia refers to the defective development or congenital absence of parotid gland tissue, which may predispose patients to several oral sequelae, such as dental caries, candidiasis, periodontal diseases, profound xerostomia, ascending sialadenitis and halitosis. It can be an isolated event or related to developmental diseases, including first and second branchial syndromes, mandibulofacial dysostosis, hemifacial microsomia, Klinefelter syndrome, Downs syndrome and Levy-Hollister syndrome (10-12,27,28).

The occurrence of ectopic parotid glands at cheek might be difficult to diagnose. It is easy to be confused with other lumps in the area of head and neck, such as venous malformations, lymphatic malformations, masseteric hypertrophy, diffuse inflammatory changes and neoplasia and lipoma etc. The regular physical examination could not give confirmed diagnosis hence imaging examination such as CT scan and MRI should be taken into consideration. Some authors pointed out that CT scan can distinctly display the position of ectopic parotid glands and other kind of salivary tissue $(16,24)$. In our case, enhanced CT scan clearly showed the location and boundaries of ectopic glands, while MRI could also has been an another appropriate approach. However, ultrasound imaging examination should not be 
neglected for patients who have chief complaints of facial swelling or cheek lumps.

Despite being one of the major salivary glands, parotid gland can be compensated by the other salivary glands (16). Treatment of the developmental abnormalities of parotid gland is highly dependent on the symptoms. If the patient has severe symptoms, such as pain, fistula, purulence and infection or significant aesthetic concerns, active surgical management could be applied to prevent further development of the ectopic glands. Conversely, if the patient has no severe symptoms mentioned above, there is no need for further treatments. In this case, the patient is only 12 -year-old who has had long period of growth and development. Bilateral ectopic parotid glands might not be the indication of parotidectomy since the resection of the gland certainly will affect function of salivary secretion and digestion. For these reasons, we believe that conservative management is the best option and suggest that needle biopsy, incisional biopsy and parotidectomy of the ectopic gland should be taken prudently to avoid invasive detection or treatment.

In sum, here we report a rare case of bilateral ectopic parotid glands on the check and a systematic review of bilateral ectopic parotid glands reported in literature. So far bilateral ectopic parotid glands case is extremely rare and only 2 cases were reported (including this case). Clinically, they usually present as slowly progressive, painless masses. Usually, ectopic bilateral parotid gland does not require any treatments, except frequent follow-ups

The occurrence of ectopic parotid glands at cheek might be difficult to diagnose and it is easily confused with other pathologies in the area of head and neck. As the literature on ectopic parotid gland was reported, etiology of ectopic parotid gland should be considered as a cause of facial mass in the clinic. Imaging is imperative for assessment the cause of cheek swelling. CT, MRI, ultrasound imaging and parotid sialography allow noninvasive diagnosis of parotid gland ectopia. If the parotid ectopic is highly suspected and the patient does not have obvious symptoms, conservative treatment and long-term observation followup are recommended. In case of aggressive growth and development, further treatments, including surgical excisions should be considered.

\section{Acknowledgments}

We thank the patient and her parents for allowing the publication of this case report. We also thank Meng-Kun
Ding, a post-graduate student, for taking several pictures of the patient and Professor Xiao-Feng Shan for his valuable suggestions on the article. We thank Dr. Vicky Yau (Stony Brook University School of Dental Medicine, USA) for checking the manuscript.

Funding: This research was funded by the National Natural Science Foundation of China (Grant numbers 81870781 and 82002878) and Peking University Hospital of Stomatology Young Foundation (Grant No. YS020219).

\section{Footnote}

Reporting Checklist: The authors have completed the CARE reporting checklist. Available at http://dx.doi.org/10.21037/ gs-20-751

Conflicts of Interest: All authors have completed the ICMJE uniform disclosure form (available at http://dx.doi. org/10.21037/gs-20-751). The authors have no conflicts of interest to declare.

Ethical Statement: The authors are accountable for all aspects of the work in ensuring that questions related to the accuracy or integrity of any part of the work are appropriately investigated and resolved. All procedures performed in studies involving human participants were in accordance with the ethical standards of the institutional and/or national research committee(s) and with the Helsinki Declaration (as revised in 2013). Written informed consent was obtained from the patient's guardian (Child's father).

Open Access Statement: This is an Open Access article distributed in accordance with the Creative Commons Attribution-NonCommercial-NoDerivs 4.0 International License (CC BY-NC-ND 4.0), which permits the noncommercial replication and distribution of the article with the strict proviso that no changes or edits are made and the original work is properly cited (including links to both the formal publication through the relevant DOI and the license). See: https://creativecommons.org/licenses/by-nc-nd/4.0/.

\section{References}

1. Higley MJ, Walkiewicz TW, Miller JH, et al. Aplasia of the parotid glands with accessory parotid tissue. Pediatr Radiol 2010;40:345-7.

2. Whyte AM, Hayward MW. Agenesis of the salivary glands: a report of two cases. Br J Radiol 1989;62:1023-6. 
3. Bhide VN, Warshawsky RJ. Agenesis of the parotid gland: association with ipsilateral accessory parotid tissue. AJR Am J Roentgenol 1998;170:1670-1.

4. Goldenberg D, Flax-Goldenberg R, Joachims HZ, et al. Misplaced parotid glands: bilateral agenesis of parotid glands associated with bilateral accessory parotid tissue. J Laryngol Otol 2000;114:883-5.

5. Antoniades DZ, Markopoulos AK, Deligianni E, et al. Bilateral aplasia of parotid glands correlated with accessory parotid tissue. J Laryngol Otol 2006;120:327-9.

6. Frommer J. The human accessory parotid gland: its incidence, nature, and significance. Oral Surg Oral Med Oral Pathol 1977;43:671-6.

7. Zarbo RJ. Surgical Pathology of the Salivary Glands. The American Journal of Surgical Pathology 1992;16:918-9.

8. Polayes IM, Rankow RM. Cysts, masses, and tumors of the accessory parotid gland. Plast Reconstr Surg 1979;64:17-23.

9. Toh H, Kodama J, Fukuda J, et al. Incidence and histology of human accessory parotid glands. Anat Rec 1993;236:586-90.

10. Taji SS, Savage N, Holcombe T, et al. Congenital aplasia of the major salivary glands: literature review and case report. Pediatr Dent 2011;33:113-8.

11. Yilmaz YF, Titiz A, Yurur-Kutlay N, et al. Congenital bilateral parotid gland agenesis in Klinefelter syndrome. J Craniomaxillofac Surg 2010;38:248-50.

12. Ferguson MM, Ponnambalam Y. Aplasia of the parotid gland in Down syndrome. Br J Oral Maxillofac Surg 2005;43:113-7.

13. Al-Talabani N, Gataa IS, Latteef SA. Bilateral agenesis of parotid salivary glands, an extremely rare condition: report of a case and review of literature. Oral Surg Oral Med Oral Pathol Oral Radiol Endod 2008;105:e73-5.

14. Sun L, Sun Z, Ma X. Congenital parotid ectopia in accessory maxilla and facial cleft anomalies: three cases report. Int J Pediatr Otorhinolaryngol 2013;77:608-12.

15. Barbuscia MA, Caizzone A, Vecchio DA, et al. Ectopic parotid: case report. G Chir 2011;32:429-33.

16. Boyd D, Bates C, Macleod RI. Ectopic parotid gland as an

Cite this article as: Xie S, Li ZM, Li SJ, Cai ZG. Congenital bilateral ectopic parotid glands: case report and systematic review of the literatures. Gland Surg 2021;10(3):1165-1170. doi: 10.21037 /gs-20-751 unusual cause of cheek swelling. Dentomaxillofac Radiol 2001;30:188-90.

17. Kaya M, Ugur KS, Dagli E, et al. Stafne bone cavity containing ectopic parotid gland. Braz J Otorhinolaryngol 2018;84:669-72.

18. Ormitti F, Ventura E, Bacciu A, et al. Unilateral ectopic parotid gland in CHARGE syndrome. Pediatr Radiol 2013;43:247-51.

19. Scherer K, Szeimies RM, Landthaler M. Ectopic parotid tissue. An unusal differential diagnosis of cystic tumors of the neck. Hautarzt 2000;51:865-8.

20. Banerjee AR, Soames JV, Birchall JP, et al. Ectopic salivary gland tissue in the palatine and lingual tonsil. Int J Pediatr Otorhinolaryngol 1993;27:159-62.

21. Perzin KH, Livolsi VA. Acinic cell carcinoma arising in ectopic salivary gland tissue. Cancer 1980;45:967-72.

22. Tsegga TM, Britt JD, Ellwanger AR. Pleomorphic adenoma of the accessory parotid gland: case report and reappraisal of intraoral extracapsular dissection for management. J Oral Maxillofac Surg 2015;73:564-70.

23. Sotorra-Figuerola D, Almendros-Marques N, EspanaTost AJ, et al. Salivary gland choristoma in the buccinator muscle: A case report and literature review. J Clin Exp Dent 2015;7:e540-3.

24. Moon WK, Han MH, Kim IO, et al. Congenital fistula from ectopic accessory parotid gland: diagnosis with CT sialography and CT fistulography. AJNR Am J Neuroradiol 1995;16:997-9.

25. Dutta $M$. The ectopic accessory parotid system with congenital cheek fistula: An overview and current update. Laryngoscope 2017;127:1351-60.

26. Currarino G, Votteler TP. Lesions of the accessory parotid gland in children. Pediatr Radiol 2006;36:1-7; quiz 84-5.

27. Inan UU, Yilmaz MD, Demir Y, et al. Characteristics of lacrimo-auriculo-dento-digital (LADD) syndrome: case report of a family and literature review. Int J Pediatr Otorhinolaryngol 2006;70:1307-14.

28. Hodgson TA, Shah R, Porter SR. The investigation of major salivary gland agenesis: a case report. Pediatr Dent 2001;23:131-4. 